\title{
The Use of Facebook in the Slovenian Local Self-Government: Empirical Evidence ${ }^{1}$
}

\author{
Tina Jukić \\ University of Ljubljana, Faculty of Administration, Slovenia \\ tina.jukic@fu.uni-lj.si \\ Blaž Svete \\ blaz.svete@gmail.com
}

\section{ABSTRACT}

The paper presents a contribution to the rapidly growing field of social networks usage in public administration organizations. Despite the increasing volume of research in this field, there is a lack of detailed empirical evidence. To address the issue, we aim here at comprehensive empirical analysis of the usage of Facebook as the most popular social networking site among Slovenian municipalities. The methodology of research is based on 21 indicators measuring usage, engagement, multichannel features, multi-media content, and the existence of a social networks usage strategy. The measurement has been performed in each of the 212 Slovenian municipalities. Their Facebook interaction has been observed in a period of six months, from November 2015 to May 2016. The analysis results reveal that only $36 \%$ of the Slovenian municipalities were present on Facebook in 2016, with almost a quarter having a zero interaction rate on their Facebook pages/profiles in the observed six-month period. In particular, one-way interaction was recorded on municipal Facebook pages, leaving considerable room for improvement as regards the usage of Facebook as a social network with the highest potential of reach and engagement in terms of number of its users. The results are useful for information and benchmarking purposes for Slovenian and foreign municipal managers.

Keywords: citizen engagement, e-participation, e-governance, municipalities, local self-government, Slovenia, social media, social networks, Facebook

JEL: L82

1 This article is a revised version of the papers entitled 'Social media usage in public administration - initial literature review' and "Facebook v slovenskih občinah: rezultati empirične raziskave" presented at the NISPAcee 2017 conference and Slovenian Dnevi slovenske uprave conference 2017. The contributions are not publicly available. 


\section{Introduction}

Social media represents "a group of Internet-based applications that build on the ideological and technological foundations of Web 2.0, and that allow the creation and exchange of user generated content" (Kaplan and Haenlein 2010, p. 61). In the context of public administration, social media is understood as Web 2.0-based technologies fostering engagement with citizens, businesses and other organisations (Criado, Sandoval-Almazan and Gil-Garcia, 2013, p. 320).

Social network platforms (e.g. Facebook) represent a (sub-) group of social media tools (Jukić and Merlak, 2017), used by 2.62 billion people worldwide. This number is expected to increase to 3.02 billion by 2021 (Statista, 2018a). In the EU, 63\% of Internet users participate in social networks (51\% in Slovenia) (Eurostat, 2017). Private companies have recognised the potential of such user concentration relatively soon and are now using social media platforms as some of the most powerful marketing tools enabling to build their image, market their services and/or products, improve customer service, and involve users in the development of new products and services.

Even though the main motive of public administration organisations' functioning is not to create profit (as it is the case in the private sector), they can benefit greatly from (active) social media platforms usage, especially in terms of improved service delivery, transparency and organisation image, as well as more inclusive policy processes. However, in most countries, public administration organisations have been rather conservative in the adoption of these tools (Jukić and Merlak, 2017). On the other hand, the topic has lately gained considerable attention in the research field (e.g. Mossberger, Wu and Crawford, 2013; Reddick and Norris, 2013; Maultasch Oliviera, 2013; Bennett and Manoharan, 2016; Mergel, 2013 etc.). Still, in-depth empirical evidence, especially in Slovenia, is relatively scarce. In Slovenia, for example, empirical research was conducted among state administration organisations in 2015 (Jukić and Merlak, 2017).

The aim of this paper is to provide in-depth empirical evidence on social networks usage in the Slovenian local self-government, i.e. municipalities. More precisely, the рарег focuses on the usage of Facebook by all (212) Slovenian municipalities. The hypothesis put on test was: "The Slovenian municipalities do not exploit the full potential of Facebook." Full potential relates to a two-way interaction between municipalities and their Facebook followers. Facebook was chosen since it has the highest number of users - 2.234 million (Statista, 2018b).

The paper is organised as follows. In the next chapter, a review of the literature in the field of social media usage in public administration is provided. In the third chapter, the methodological framework and the results of the research measuring Facebook usage in Slovenian municipalities are presented. Finally, in the discussion, suggestions for further research are given. 


\section{Literature Review}

The literature on social media usage in public administration organisations has increased greatly in the last five years. Still, a lack of empirical evidence can still be noticed. The approaches taken so far differ mainly in terms of: (1) geographical focus, (2) social media evaluated, (3) measurement unit (e.g. local government, state agencies, selected departments, etc.), and (4) research focus (e.g. adoption rate, adopting factors, situation in a specific area, such as emergency management, etc.).

Most often, the research in this field has been conducted in the US. Mossberger, Wu and Crawford (2013) analysed the usage of social media in large US cities in the period of 2009 and 2011. Their measurement was performed indirectly, i.e. through the presence of links to cities' social media accounts on their websites. Their results revealed that, in 2011, approximately $90 \%$ of the observed cities have had established Facebook and Twitter presence, and the majority of them were using YouTube as well. All cities with established Facebook/Twitter presence were enabling other users to post comments on their social media channel. In the same year (2011) the research on social media usage in US local government has been performed by Reddick and Norris (2013), who came to the conclusion that two thirds of the observed organisations have established social media presence (mainly via Facebook and Twitter), but one-way interaction dominated. A year later, social media usage in the US local governments was performed by Maultasch Oliviera (2013); similarly, their results revealed that the majority of cities (88\%) adopted at least one social media channel with Facebook and Twitter being most frequent. Feeney and Welch (2016) also performed their research in among the US local governments in 2012. Similarly as Reddick and Norris (2013), they concluded that one-way interaction was the main reason for social media presence of the observed organisations, however the positive trend of using social for getting feedback on service quality, internal and enabling/Facilitating citizen participation has also been noticed. The increasing adoption of social media in US local governments (and elsewhere) raises the need for policies guiding the use of social media and enabling transparent engagement with citizens. Such policies were in focus of the research by Bennett and Manoharan (2016), who revealed that many US cities lacked social media policies guiding the usage thereof, despite the fact that most of them integrated social media in their daily operations (see also Mergel, 2013).

A relatively high level of social media adoption has been noticed in Romania (Urs, 2016) and Lithuania (Sinkienè and Bryer, 2016) as well. Urs (2016) focused his research on the Facebook accounts of Romanian city halls. 17\% of them did not establish Facebook presence in the observed period. Five of those with established Facebook presence were mostly inactive on their accounts (with less than five published posts) and 19 city halls (40\%) had more than 100 posts published over 454 days (574 on average). Sinkienè and Bryer (2016), who focused on Facebook adoption in Lithuanian municipalities, came to the conclusion that the majority (77\%) of municipalities used Facebook, 
with most of them (41\%) creating their accounts in 2015 (year of elections) or later. Mainly one-way interaction with very little feedback has also been noticed in their research. The latter (i.e. one-way interaction) holds true for Egyptian government's social media usage (Abdelsalam et al., 2013) and Czech regions (Špaček, 2017).

Some research analysed the barriers to social media adoption in public administration organisations. In this context, Mergel and Bretschneider (2013) developed a three-stage adoption process for social media usage in government: (1) intrapreneurship and informal experimentation, (2) constructive chaos, and (3) institutionalisation. Table 1 summarises the main characteristics of all three stages.

Table 1: Three-stage process model for social media adoption in government organisations

\begin{tabular}{|c|c|c|c|c|}
\hline & Role of Organizational Structure & Role of Technology & Role of Outcomes & Organizational Response \\
\hline $\begin{array}{l}\text { Stage 1: Decentralized, } \\
\text { informal experimentation }\end{array}$ & $\begin{array}{l}\text { Important to allow for experi- } \\
\text { mentation }\end{array}$ & $\begin{array}{l}\text { Following outside best practices (repli- } \\
\text { cation of successes) }\end{array}$ & $\begin{array}{l}\text { Early tests lead to first } \\
\text { insights }\end{array}$ & $\begin{array}{l}\text { Unsanctioned accounts, not on } \\
\text { the organizational radar screen }\end{array}$ \\
\hline Stage 2: Coordinated chaos & $\begin{array}{l}\text { Important to consolidate het- } \\
\text { erogeneity of use }\end{array}$ & $\begin{array}{l}\text { Increases in importance but mainly be- } \\
\text { cause of innovative use and routines }\end{array}$ & $\begin{array}{l}\text { Highly important to } \\
\text { create business cases }\end{array}$ & $\begin{array}{l}\text { Task force, steering committee, } \\
\text { draft policies/strategies }\end{array}$ \\
\hline $\begin{array}{l}\text { Stage 3: Institutionalization } \\
\text { and consolidation }\end{array}$ & New organizational structures & $\begin{array}{l}\text { Set of accepted technologies versus } \\
\text { wide range of innovative technolo- } \\
\text { gies to support different purposes }\end{array}$ & $\begin{array}{l}\text { Important for future } \\
\text { resource allocation }\end{array}$ & $\begin{array}{l}\text { Formalized institutions, work } \\
\text { assignments, tasks, roles, } \\
\text { dedicated resource allocation, } \\
\text { formal social media policies }\end{array}$ \\
\hline
\end{tabular}

Source: Mergel and Bretschneider (2013, p. 397).

\section{Facebook Usage in the Slovenian Local Self-Government}

\subsection{Methodological framework}

The research analysed the Facebook profiles of all 212 Slovenian municipalities, focusing on the content published over a period of six months, from 15 November 2015 to 14 May 2016.

For each municipality, 21 indicators were measured and classified into five groups:

1 Usage

a) Presence of municipality on Facebook

b) Type of presence: page or profile; organisations can create a page or a profile on Facebook. The Facebook page is meant primarily for organisations, while the Facebook profile is meant for citizens/private users (still, some organisations decided to establish a profile instead of a page.). Facebook users can 'like' a page and do not need any confirmation from the organisation. On the contrary, when Facebook users send requests for friendship to other Facebook profile owners, they need confirmation from the profile owner. Friendship requests were sent to municipalities owning a Facebook profile with the intention to get a full insight in their Facebook activities. 
c) Year of entry on Facebook

d) Number of posts published from 15 November 2015 to 14 May 2016

e) Types of posts: (1) posts calling for cooperation/ opinions through Facebook, (2) posts calling for cooperation/ opinions through other channels (e.g. e-mail), (3) posts providing information on past events, (4) posts providing information on upcoming events, and (5) other posts.

f) Topical orientation of posts: (1) food, cooking, health, sports, recreation, (2) culture, cultural and social events, (3) infrastructure, (4) tourism, (5) the work of the municipal administration and council, (6) other.

2 Multi-channel features

a) Availability of link to the Facebook page on the organisation's web page

b) Availability of link to the organisation's web page on the Facebook page

3 Engagement

a) Number of likes/friends on 15 May 2016

b) Possibility of writing on the Facebook page by other users

c) Number of posts submitted by other Facebook users

d) Number of likes of posts

e) Number of shares of posts

f) Number of comments on posts

g) Number of comments submitted from municipality

h) Number of comments submitted from other users (citizens, organisations)

i) Page level interaction rate

j) Number of polls

k) Number of prize contests

4 Multi-media content: number of posts with multi-media content (images, videos, audio)

5 Strategy: existence of social networks usage strategy (an e-mail with this question was sent to the municipalities with established Facebook presence)

\subsection{Presentation of results}

\subsubsection{Usage and multi-channel features}

Results of the analysis show that 76 or $36 \%$ of Slovenian municipalities are present on Facebook. The results below relate to municipalities present on Facebook.

The first municipality that joined Facebook was Poljčane (4444 residents, northeaster Slovenia) in 2009. 12 (16\%) municipalities followed in 2010 and 10 (13\%) in 2011. 13 (17\%) municipalities began to use Facebook in 2012 and 
another five (7\%) in 2013. The largest share of municipalities joined Facebook in 2014 (21\%) and 2015 (20\%). In 2016, four new municipalities joined Facebook by 15 May.

66 municipalities (87\%) established a Facebook presence with a page, while the remaining 10 had Facebook profiles designed primarily for citizens/private users and requiring the organisation's approval to follow its full content (except if the profile is set as public, which is rarely the case and never in our research).

Once a Facebook page is set up, the challenge is to attract the target groups (i.e. fans, the target group of messages/posts published on the Facebook page). One of the basic principles in the digital marketing is to put the link to the Facebook page on the website of the organisation, thus informing the website visitors that the organisation is present on Facebook as well, and that they can follow its posts via additional channel(s). On the other hand, Facebook, in the context of web marketing, is a good channel to attract visitors to the organisation's website (with the link in the "About" section which is devoted to the presentation of the organisation). 71 of the municipalities present on Facebook had a link to their website in the section About. Only 46 municipalities (61\%) created a link to their Facebook site/profile on their official web site.

The main feature used by Facebook users (be it individuals, businesses, or public organisations) are posts - messages published on the wall/timeline of a specific Facebook page. On the Facebook pages/profiles of the municipalities, 9350 posts were posted between 15 November 2015 and 14 May 2016, which on average represents one post per municipality per day. On average, 51 posts were posted per day on the municipalities' Facebook pages or profiles. Most posts were posted by the municipality of Velenje with 32736 residents, which lies in northeaster Slovenia (572, 3 posts per day on average). Five municipalities did not publish any post in the period concerned. Literature for public administration does not specify the optimal number of posts per day because it very much differs from case to case. Nevertheless, some experts have determined, based on their research, the range of posts published in one day that organisations in the private sector should consider on Facebook. SocialBakers found out in their survey that the largest enterprises posted on social media on average one post per day. Thus, they proposed one to two posts per day (Rezab, 2011). Based thereon, it was examined how many municipalities provided for the proposed frequency of publishing posts. In the municipalities that began to use Facebook after 15 November 2015, the number of days from the date of entry on Facebook to 14 May 2016 was taken into account. Based on the frequency of posts suggested by the Rezab (2011), it was examined how many municipalities were consistent with this proposal. The results show that only $12(16 \%)$ of the municipalities that used Facebook were consistent with the proposed frequency of published posts per day: Brda, Črna na Koroškem, Domžale, Ivančna Gorica, Izola, Kranj, Ljubljana, Medvode, Nova Gorica, Ruše, Šentilj and Trbovlje; these municipali- 
ties don't have a homogeneous geographical position. Six (8\%) municipalities posted with greater frequency than proposed. 58 municipalities posted less posts than proposed (Figure 1). The calculation of correlation between the size of the municipalities (number of residents) and the number of their Facebook posts reveals a weak correlation (Pearson coefficient 0.26).

Figure 1: Shares of municipalities present on Facebook based on their frequency of posting $(n=76)$

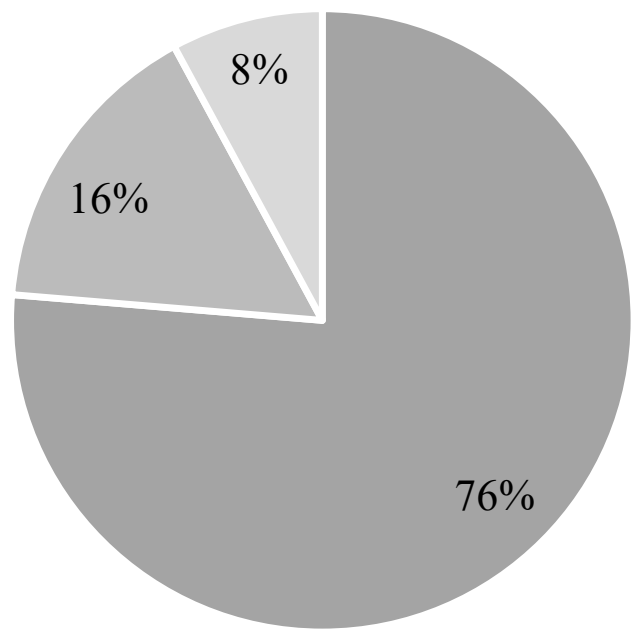

Source: own calculations.

\subsubsection{Purpose of the posts}

The posts on Facebook walls of the municipalities were categorised by type of post (Table 3). Seven posts called for cooperation/opinions through Facebook. 32 posts called for cooperation/opinions through other channels (e.g. e-mail). 1867 posts were related to past events and 3417 posts provided information on upcoming events. The largest share of posts were 'other' posts. The 4027 posts categorised as other posts accounted for $43 \%$ of total posts. The result suggests that in preparing the methodology, the category other posts should have been further split into more specific categories.

Posts calling for cooperation/opinions through Facebook accounted for $0.07 \%$ of the total posts. Posts calling for cooperation/opinions through other channels (e.g. e-mail) accounted for $0.34 \%$ of total posts. $20 \%$ of total posts were posts that provided information on past events while $37 \%$ provided information on upcoming events.

The posts calling for cooperation/opinions were 39 in total, posted by 17 municipalities (22\% of the Slovenian municipalities present on Facebook). The municipality Markovci (eastern Slovenia, 3997 residents) mainly posted posts calling for cooperation/opinions (seven). The municipality that posted the 
largest share of posts calling for cooperation/opinions was Beltinci (also eastern Slovenia, 8267 residents) with 4\% (5 out of 129 posts in total).

Facebook enables municipalities to inform the public about events that occur in the municipality. 68 municipalities posted at least one post to inform about events. The total number of such posts was 5284 or $57 \%$ of all posts posted on municipalities Facebook walls. The Slovenian municipalities mostly informed about upcoming events (65\% of posts informing about events). 53 out of 68 municipalities that posted at least one post to inform about events had on their wall more posts about upcoming events than about past events. Data on posts by purpose are presented in Table 4.

Table 2: Purpose of posts on municipalities' Facebook pages/sites from 15 November 2015 to 14 May $2016(n=9350)$

\begin{tabular}{|l|r|r|}
\hline & No. of posts & $\%$ of posts \\
\hline $\begin{array}{l}\text { Posts calling for cooperation/opinions through } \\
\text { Facebook }\end{array}$ & 7 & $0.07 \%$ \\
\hline $\begin{array}{l}\text { Posts calling for cooperation/opinions through } \\
\text { other channels (e.g. e-mail) }\end{array}$ & 32 & $0.34 \%$ \\
\hline Posts informing about past events & 1867 & $20 \%$ \\
\hline Posts informing about upcoming events & 3417 & $37 \%$ \\
\hline Other posts & 4027 & $43 \%$ \\
\hline Total & 9350 & $100 \%$ \\
\hline
\end{tabular}

Source: own calculations.

\subsubsection{Topical orientation of the posts}

The posts were divided into categories according to their content. Posts on the municipalities Facebook walls mostly related to culture and cultural and social events. The total number of such posts was 4130 (44\% of all analysed posts). Posts related to food, health, cuisine, sports and recreation (1263 in total) accounted for $14 \%$ of all posts. For a municipality it is important to inform citizens about the work of the municipal administration and council and about municipal infrastructure: 1216 posts related to the work of the municipal administration and council (13\% of total posts). 590 posts (6\%) informed about infrastructure. Municipalities inform the least on tourism, which for some municipalities (e.g. Bled, north-western Slovenia, 8088 residents) can be crucial as they are very dependent on tourism. 203 posts related to tourism, which was only $2 \%$ of total posts. $21 \%$ were posts on other contents (Table 4 ). 
Table 3: Number of posts by content on municipalities' Facebook pages/sites from 15 November 2015 to 14 May $2016(n=9350)$

\begin{tabular}{|l|r|r|}
\hline & No. of posts & $\%$ of posts \\
\hline Food, health, cuisine, sports and recreation & 1263 & $14 \%$ \\
\hline Culture, cultural and social events & 4130 & $44 \%$ \\
\hline Infrastructure & 590 & $6 \%$ \\
\hline Tourism & 203 & $2 \%$ \\
\hline Work of the municipal administration and council & 1216 & $13 \%$ \\
\hline Other & 1948 & $21 \%$ \\
\hline Total & 9350 & $100 \%$ \\
\hline
\end{tabular}

Source: own calculations.

\subsubsection{Engagement}

The number of likes or friends varies significantly from municipality to municipality. On 15 May 2016, only the municipality of Ankaran (south-western Slovenia, 3237 residents) had 0 friends. That was probably the result of not actively using their profile and not confirming friendship requests. The municipality with the lowest number of likes was east-positioned Duplek with 6755 residents (40 likes). Most likes were recorded by the largest Slovenian municipality Ljubljana (9789 likes). The average number of likes or friends of the Slovenian municipalities on Facebook was 1178. The calculation of correlation between the size of the municipalities (number of residents) and the number of their followers reveals a very strong correlation (Pearson coefficient 0.85).

A municipality's openness is also reflected by allowing other Facebook users to write posts on the wall of the municipality. $79 \%$ of the municipalities present on Facebook allowed other users to write on their walls. Yet, only a few users chose to do so. 138 posts were initiated by other Facebook users, accounting for $1 \%$ of the total number of posts. The posts initiated by other users were posted on the walls of seven (geographically heterogeneous) municipalities: Vodice, Straža, Kuzma, Kostel, Hrpelje - Kozina, Dobrovnik and Dobje. The municipality with the largest number of such posts was Kostel (southeast Slovenia, 643 residents) with 44 posts (75\% of all posts on their wall).

User engagement (Table 5) was measured by the number of comments on posts, the number of shares, and the number of likes. Facebook users liked the posts on municipalities' Facebook walls 142273-times (15 likes per post on average). The municipality of Ljubljana had the largest number of likes on its posts: 21000 or $73 \%$ likes per post. The calculation of correlation between the number of Facebook followers and the number of likes on Facebook posts reveals a very strong correlation (Pearson coefficient 0.88 ). 
The analysed posts were shared 13114-times, which is on average one share per post. The municipality with the most shares was (again) Ljubljana, with seven shares per post and a total number of 1931 shares. It is followed by Črna na Koroškem with 3342 residents (4) and Žiri with 4846 residents (4).

Table 4: Number of likes, shares and comments on posts posted on municipalities' Facebook pages/profiles from 15 November 2015 to 14 May $2016(n=9350)$

\begin{tabular}{|l|r|r|}
\hline & Total no. for all posts & Avg. no. per post \\
\hline Likes & 142273 & 15 \\
\hline Shares & 13114 & 1 \\
\hline Comments & 7287 & 1 \\
\hline
\end{tabular}

Source: own calculations.

There were altogether 7287 comments on posts in the observed period. This means that there was on average one comment per post. Again, the municipality of Ljubljana had the largest number of comments per post, i.e. five, followed by the fourth biggest Slovenian municipality Kranj (3) and the fifth smallest Slovenian municipality Kostel (3). The calculation of correlation between the number of Facebook followers and the number of comments on the Facebook posts reveals a very strong correlation (Pearson coefficient 0.83).

Of all comments, 6698 were written by other Facebook users, which accounts for $92 \%$ of all comments (Table 6 ). The municipalities posted 589 comments ( $8 \%$ of all comments). With 126 comments, Ljubljana had the most comments by municipality, while Kranj had the highest average of comments by municipality per post with 0.45 comment. Most comments from the municipality compared to comments from other users were posted by Trzin with 3862 residents (Central Slovenia) (61\%). Ljubljana had the most comments from other users (1364 comments), which was also the highest average of comments from other users per post (5 comments per post).

Table 5: Number of comments on posts on municipalities' Facebook pages/profiles from 15 November 2015 to 14 May $2016(n=7287)$

\begin{tabular}{|l|r|r|}
\hline & No. of comments & $\%$ of comments \\
\hline Comments written by municipalities & 589 & $8 \%$ \\
\hline $\begin{array}{l}\text { Comments written by other } \\
\text { Facebook users/followers }\end{array}$ & 6698 & $92 \%$ \\
\hline Total & 7287 & $100 \%$ \\
\hline
\end{tabular}

Source: own calculations. 
In order to evaluate the whole page engagement/interaction rate, the following formula was applied, where $L$ stands for all post likes, C for all post comments, $\mathrm{S}$ for all post shares, $\mathrm{F}$ for page fans, and $\mathrm{P}$ for all page posts in the observed period. The same formula is used by Quintly software for social media analytics (Quintly, 2018).

The results reveal that almost a quarter of the municipalities with established Facebook presence (24\%) has a zero interaction level, most of them (41\%) have a $1 \%$ interaction level, $17 \%$ have a $2 \%$ interaction level, $12 \%$ have a $3 \%$, $7 \%$ have a $4 \%$, and $1 \%$ has a $7 \%$ level of interaction. While it is hard to say what is a good interaction level in the context of public administration organisations, it is worth mentioning that the average rate for all private sector industries is 0.21 (Gottke, 2017). Nevertheless, these results should be observed with some reservation or in a broader context. Namely, the highest level of interaction was recorded by the fourth smallest Slovenian municipality Kobilje (a municipality in eastern Slovenia with 561 residents), but that was due to a very high number of post likes (630) and a low number of posts (27). This means that in this specific case, the municipality was rather inactive with post publishing, but each post received a relatively high users' attention.

Prize contest enables to quickly and easily attract new followers to a Facebook profile or page (Marrs, 2017). Among all posts, 17 posts included a prize contest launched by the municipalities. Eight municipalities posted prize contests, with Kranj (the fourth biggest Slovenian municipality, positioned in north-western Slovenia) posting the highest number thereof - six.

Municipalities can promote the participation of citizens also through surveys. There were 29 surveys published by 16 municipalities. Most surveys were posted by the municipality of Domžale (Central Slovenia, 35195 residents), namely four. All posts about surveys had web links to external websites.

\subsubsection{Multi-media content}

When publishing content on social networks, it is important that the posts contain multimedia content, such as images, video and audio. These kinds of posts attract more attention of readers (Lesser, 2017). 5241 out of 9350 posts contained multimedia content, accounting for $56 \%$ of all analysed posts (Figure 2). Of the municipalities that actively used Facebook (on average, they posted at least one post per day on their Facebook wall), the municipality of Medvode with 15979 residents had the highest share of posts with multimedia content $-88 \%$. It is followed by Ljubljana (85\%) and Trbovlje (84\%). 
Figure 2: Share of posts on municipalities' Facebook pages/profiles with multimedia content posted from 15 November 2015 to

14 May $2016(n=9350)$

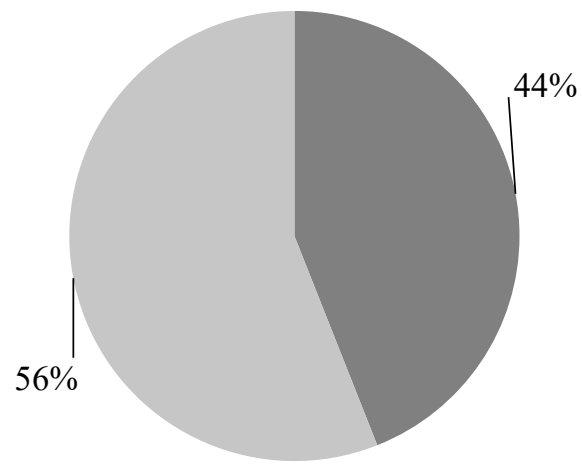

Source: own calculations.

\subsubsection{Strategy for using social networks}

An e-mail was sent to the municipalities with established Facebook presence asking if they had established a social networks usage strategy in their municipality.

45 municipalities (59\%) answered the question, with three of them (4\% of those with established Facebook presence) saying they did have such strategy, while 42 (55\%) did not (Figure 3).

Some municipalities established ground rules and a vision, but rather loosely. Two municipalities (Medvode and Ljubljana) established 'unwritten' rules.

Figure 3: Number of municipalities with established social networks usage strategy ( $n=76)$

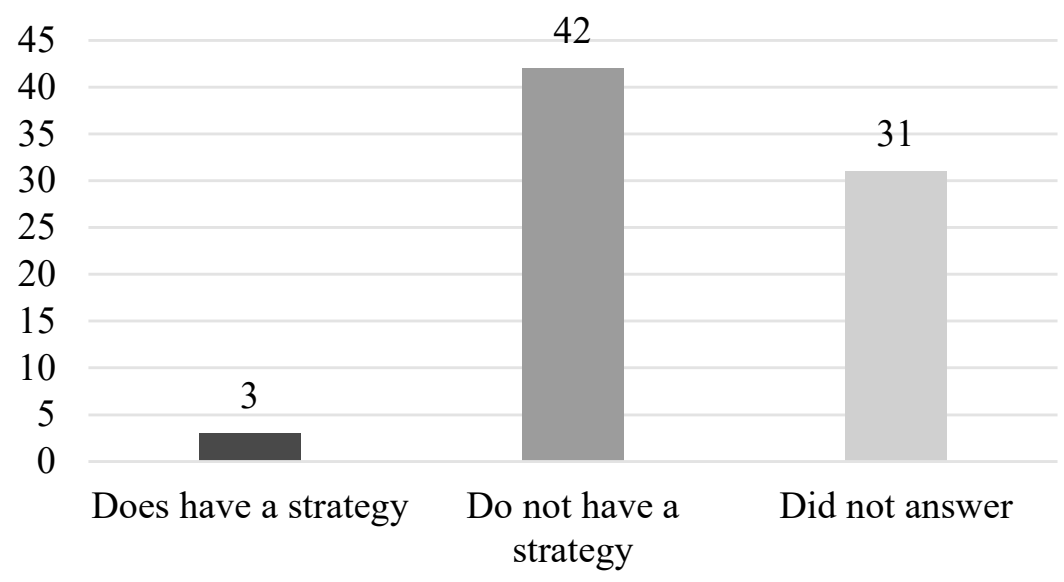

Source: own calculations. 


\section{Discussion and Suggestions for Future Research}

While private entities have recognised social media and, specifically, social networks as a very valuable marketing tool, public organisations (including Slovenian municipalities), on the other hand, seem to be still experimenting. The initial hypothesis can be confirmed - the Slovenian municipalities do not exploit the full potential of Facebook as a social networking platform with the highest potential of reach and engagement in terms of number of its users. First, only $36 \%$ of them were present on the Facebook in 2016 . Second, among those with established Facebook presence, less than two thirds (61\%) created a link to their Facebook page on their official web site. Third, the frequency of publishing content has also revealed room for improvements. Fourth, $21 \%$ of municipalities did not allow other users to write on their Facebook walls; in addition, less than $0.5 \%$ of all posts published in the observed period, called for cooperation/opinions (i.e. two-way interaction) - which may also be the reason why only a few users chose to. Finally, almost a quarter of the municipalities with established Facebook presence, had a zero interaction level in the period observed.

Based on the three-stage adoption process for social media usage in government developed by Mergel and Bretschneider (2013) and presented in the second chapter, it can be concluded that the Slovenian municipalities are at the first stage - intrapreneurship and informal experimentation. In order to proceed onto the next stages, they will have to adopt a social media strategy and related guidelines. This may be challenging for many of them, since more than half (52\%) of the Slovenian municipalities has less than 5000 residents and thus smaller administrative capacities compared to larger ones. Since (ргорег) administering of social media communication is time-consuming, most municipalities could establish an editorial system in which content is created by several employees - this indeed requires training in the field of social media communication, but not necessarily additional staff.

Even though the comparison with other countries is limited due to different methodological approaches and different administrative systems, some common (and eloquent) points can be identified, but should be observed with some reservation. First, only $36 \%$ of the Slovenian municipalities established Facebook presence, which is much less than in the US. In fact, almost $90 \%$ of the US cities observed by Mossberger, Wu and Crawford (2013) were on Facebook in 2011. Even though other research in the US revealed a bit lower adoption rate of social networks platforms in local government units - e.g. two thirds, as revealed by Reddick and Norris (2013) - the results put the Slovenian local self-government in a weaker position. The same can be concluded when compared to Romania, Lithuania and Egypt. Mainly one-way interaction on Facebook pages, on the other hand, was identified in most other studies observing this or related indicators, and the same holds true for the low level of social media strategy adoption, which is a weakness identified not only in Slovenia, but also in the US. 
The main shortcoming of our research is the classification of Facebook posts on municipal Facebook pages according to their type and content. Namely, a large portion thereof fell into the category 'other'. This leaves room for improvement in terms of posts content and improved coding scheme.

Still, the results are very eloquent and useful for benchmarking purposes for municipal managers in Slovenia and abroad. 


\section{References}

Abdelsalam, H. M., Reddickb, C. G., Gamalc, S. and Al-shaarc, A. (2013). Social media in Egyptian government websites: Presence, usage, and effectiveness. Government Information Quarterly, 30(4), pp. 406-416.

Bennett, L. V. and Manoharan, A. P. (2016). The Use of Social Media Policies by US Municipalities. International Journal of Public Administration, 40(4), pp. 1-12. At <http://www.tandfonline.com/doi/abs/10.1080/01900692.2015.111 3182>, accessed 20 November 2016.

Criado, J.I., Sandoval-Almazan, R. and Gil-Garcia, J. R., 2013. Government innovation through social media. Government Information Quarterly, 30(4), pp. 319-326.

Eurostat (2017). Digital economy \& society in the EU - A browse through our online world in figures. At < http://ec.europa.eu/eurostat/cache/infographs/ict/ index.html>, accessed 26 April 2018.

Feeney, M. K and Welch, E. W. (2016). Technology-Task Coupling: Exploring Social Media Use and Managerial Perceptions of E-Government. American Review of Public Administration 2016, 46(2), pp. 162-179.

Gottke (2017). Average Interaction Rate on Facebook: Industry Insights. At <https://www.quintly.com/blog/2017/08/average-interaction-rate-facebook-industry-insights>, accessed 26 April 2018.

Jukić, T. and Merlak, M. (2017). The Use of Social Networking Sites in Public Administration: The Case of Slovenia. The Electronic Journal of e-Government, 15(1), pp. 2-18.

Kaplan, A. M. and Haenlein, M., 2010. Users of the world, unite! The challenges and opportunities of Social Media. Business Horizons, 53(1), pp. 59-68.

Lesser, P. (15. 1. 2017). Use Multimedia on Facebook to Promote Your Business. At <https://www.allbusiness.com/use-multimedia-on-facebook-to-promote-your-business-15570739-1.html>, accessed 15 January 2017.

Marrs, M. (2017). 7 Ways to Use Facebook for Marketing. At <http://www.wordstream.com/blog/ws/2013/04/15/Facebook-marketing>, accessed 16 January 2017.

Mergel, I. and Bretschneider, S. I. (2013). A Three-Stage Adoption Process for Social Media Use in Government. Public Administration Review, 73(3), pp. 390-400.

Mossberger, K., Wu, Y. and Crawford, J. (2013). Connecting citizens and local governments? Social media and interactivity in major U.S. cities. Government Information Quarterly, 30(4), pp. 351-358.

Oliveira, G. H. M. and Welch, E. W. (2013). Social media use in local government: Linkage of technology, task, and organizational context. Government Information Quarterly, 30(4), pp. 397-405.

Quintly (2018). Calculating Interaction Rate. At <https://support.quintly.com/ hc/en-us/articles/115001703274-Calculating-Interaction-Rate>, accessed 26 April 2018.

Reddick, C. G. and Norris, D. F. (2013). Social media adoption at the American grass roots: Web 2.0 or 1.5?. Government Information Quarterly, 30(4), pp. 498-507.

Rezab, J. (19. 4. 2011). How often should you post on your Facebook pages?. At <https://www.socialbakers.com/blog/147-how-often-should-you-post-on-your-facebook-pages>, accessed 16 January 2017. 
Sinkiene, J. and Bryer, T. A. (2016). Social Media Adoption and Performance: A First Look at Lithuanian Municipalities. In: $24^{\text {th }}$ NISPAcee Annual Conference. Zagreb, Croatia, 19-21 May 2016.

Statista (2018a). Number of social network users worldwide from 2010 to 2021 (in billions). At https://www.statista.com/statistics/278414/number-of-world wide-social-network-users/, accessed 26 April 2018.

Statista (2018b). Most popular social networks worldwide as of April 2018, ranked by number of active users (in millions). At <https://www.statista.com/stat istics/272014/global-social-networks-ranked-by-number-of-users/>, accessed 26 April 2018.

Špaček, D. (2017). Social media usage and performance: the case of Czech regions. In: Innovation governance in the public sector. Kazan: NISPAcee, 2017.

Urs, N. (2016). Online Services and Social Media Use in Romanian Cities: Can We See a Pattern? In: 24 ${ }^{\text {th }}$ NISPAcee Annual Conference. Zagreb, Croatia, 19-21 May 2016. 